INTERNATIONAL MONETARY FUND
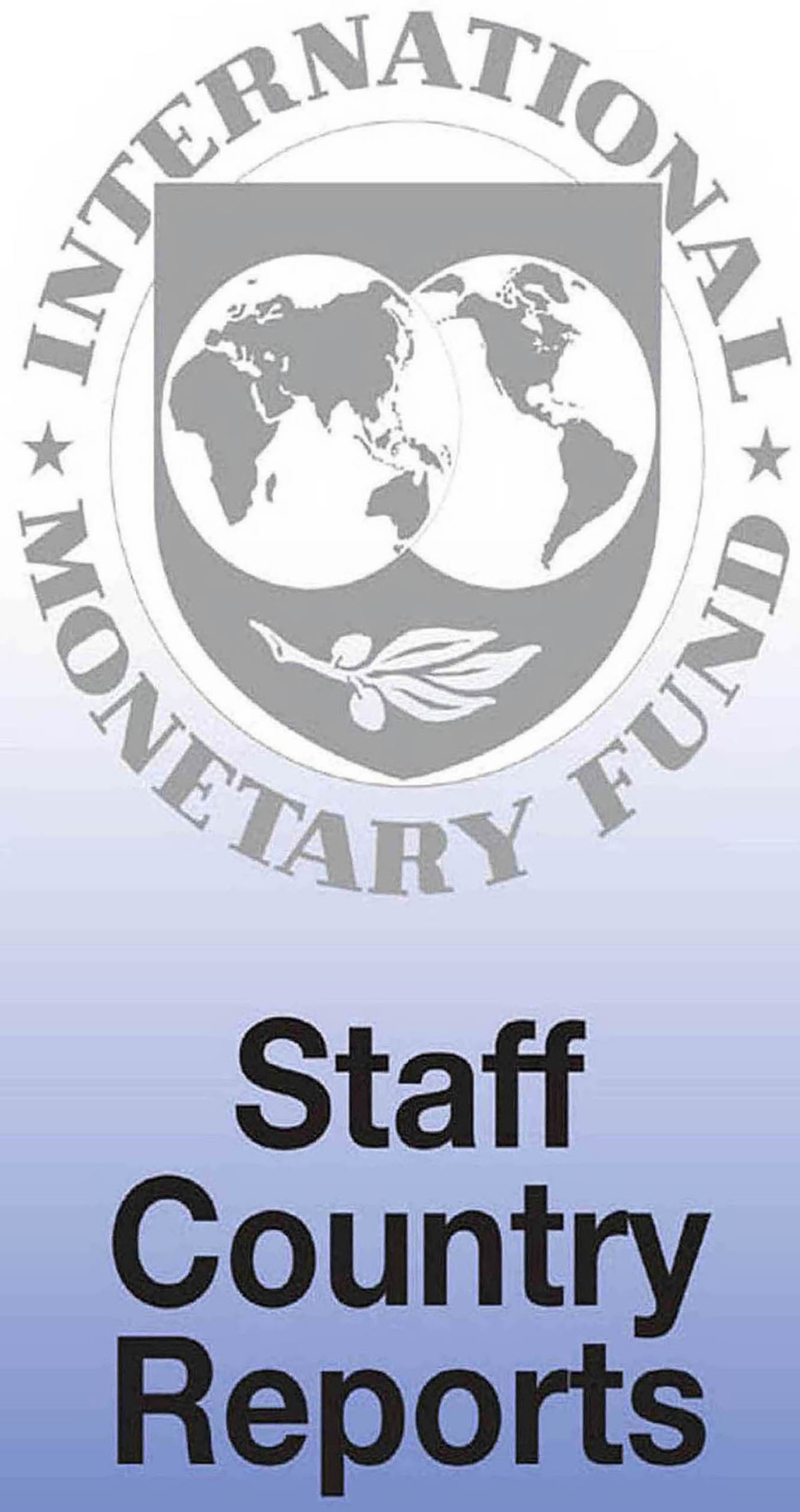


\section{Belgium: Technical Note on Securities Markets Regulation and Supervision}

This paper was prepared based on the information available at the time it was completed on May 16, 2013. The views expressed in this document are those of the staff team and do not necessarily reflect the views of the government of Belgium or the Executive Board of the IMF.

The policy of publication of staff reports and other documents by the IMF allows for the deletion of market-sensitive information.

Copies of this report are available to the public from

International Monetary Fund • Publication Services

700 19th Street, N.W. • Washington, D.C. 20431

Telephone: (202) 623-7430 • Telefax: (202) 623-7201

E-mail: publications@imf.org • Internet: http://www.imf.org

\section{International Monetary Fund \\ Washington, D.C.}




\section{INTERNATIONAL MONETARY FUND}

\section{BELGIUM}

\section{FINANCIAL SECTOR ASSESSMENT PROGRAM UPDATE-}

May 16, 2013

\section{TECHNICAL NOTE-SECURITIES MARKETS REGULATION AND SUPERVISION}

\section{EXECUTIVE SUMMARY}

This report considers how the Belgian authorities have responded to key changes in securities markets and regulation since the $\mathbf{2 0 0 6}$ Financial Sector Assessment Program (FSAP) analysis has been undertaken. The Financial Services and Markets Authority's (FSMA) response to changes in regulatory architecture and its initiatives in the regulation of structured products are evaluated. Further, the report looks at how the authorities have addressed new International Organization of Securities Commissions (IOSCO) Principles relating to systemic risk and reviewing the regulatory perimeter (IOSCO Principles 6 and 7). The note is based on a self assessment prepared by the FSMA as well as interviews with FSMA staff, regulated firms, industry associations, consumer groups and their advisors

The authorities have generally addressed or made good progress in addressing the recommendations of the $\mathbf{2 0 0 6}$ FSAP. In a number of cases, this has been done through transposition of European Directives into Belgian law. The FSMA should ensure it continues to monitor and respond to market developments affecting the Belgium financial services market. The FSMA is building its skills and competency in monitoring and analyzing market developments in Belgium and developments regionally and globally which affect Belgium. It should ensure it builds on these competencies to drive timely responses to emerging and systemic risks.

Formal structures are needed to embed important processes relating to identifying and managing emerging and systemic risks. Formalization of the arrangements for cooperation between the FSMA and the National Bank of Belgium (NBB) is ongoing. A broad memorandum of understanding (MOU) governing this cooperation came into effect in March 2013, together with a protocol for implementation of cooperation. The FSMA will benefit from operationalizing structures around risk identification and collaboration with the National Bank of Belgium (NBB). An Emerging Risk Committee should be established to assist the FSMA in identifying new and systemic risks in its areas of responsibility and guide the organization in responding to those risks. Implementation of the MOU will over time improve effectiveness of the new architecture. 
The regulatory regime for complex products should be extended to other products which are assessed as posing significant risks to investors. Investors will benefit from an extension of the complex products regime introduced by the FSMA in 2011 to other products posing significant risks. The regime could be based on hard law or as a continuation of the current voluntary Moratorium. We note the Moratorium has been effective in achieving its goals. Recommendations of the mission are summarized in Table 1.

Going forward, the FSMA should build on its existing work in relation to investor education and investor protection initiatives. The FSMA has focused on the design of a number of investor education and investor protection initiatives. The design of these initiatives is sound. The FSMA should give priority to resourcing effective execution of these programs.

The key recommendations of this report are summarized in Table 1. 
Table 1. Detailed Policy Recommendations

\begin{tabular}{|c|c|}
\hline Immediate Action & Priority \\
\hline $\begin{array}{l}\text { Cooperation and Collaboration between the FSMA and the NBB. The new MOU and protocol } \\
\text { between the FSMA and the NBB should be supplemented by liaison arrangements to embed the } \\
\text { protocols into processes. The authorities should remove legal impediments to information } \\
\text { sharing as a matter of priority. }\end{array}$ & High \\
\hline $\begin{array}{l}\text { Systemic and Emerging Risks. The FSMA should establish a Committee to monitor emerging } \\
\text { and systemic risks in its areas of responsibility. }\end{array}$ & High \\
\hline \multicolumn{2}{|l|}{ Short Term Action } \\
\hline $\begin{array}{l}\text { Investor Education. The FSMA should follow through on implementation of its investor } \\
\text { education programs. The programs should make greater use of social media in communicating } \\
\text { to target groups. The programs should also be appropriately resourced. }\end{array}$ & Medium \\
\hline $\begin{array}{l}\text { Investor Protection. The FSMA should continue to give initiatives in this area priority with a } \\
\text { particular focus on mystery shopping and the regulation of financial planners. }\end{array}$ & Medium \\
\hline $\begin{array}{l}\text { Markets in Financial Instruments Directive (MiFID) Conduct Supervision. The FSMA should } \\
\text { ensure the MiFID conduct audit process is sufficiently resourced to ensure adequate coverage } \\
\text { and rigor in assessments. }\end{array}$ & High \\
\hline $\begin{array}{l}\text { Complex Products Moratorium. The authorities should consider extending the Moratorium to } \\
\text { other products posing significant risks to investors. The FSMA should consider reviewing the } \\
\text { carve-out threshold applicable under current arrangements. }\end{array}$ & Medium \\
\hline \multicolumn{2}{|l|}{ Medium Term Action } \\
\hline $\begin{array}{l}\text { Level Playing Field. The FSMA should continue to give priority to a level playing field across its } \\
\text { areas of responsibility. Once European Directives are transposed into Belgian law, early action } \\
\text { should be taken to include insurance firms and insurance intermediaries in the FSMA's MiFID } \\
\text { conduct audit programs. }\end{array}$ & Medium \\
\hline $\begin{array}{l}\text { Unlisted Issuers. The FSMA should monitor issues relating to unlisted entities, assess the extent } \\
\text { of the risks posed by lower disclosure standards to investors in these issues and appropriately } \\
\text { address those risks. (pp 4-5, 36-37) }\end{array}$ & Medium \\
\hline $\begin{array}{l}\text { Prudential Supervision. The intensity and design of micro-prudential supervision programs } \\
\text { should be kept under review. Consideration should be given to increasing the number of on-site } \\
\text { visits. }\end{array}$ & Medium \\
\hline $\begin{array}{l}\text { Addressing Arbitrage Risks. The NBB and the FSMA should together monitor, on an ongoing } \\
\text { basis, the arbitrage risks posed by the current distribution of responsibilities. }\end{array}$ & Medium \\
\hline
\end{tabular}




\section{CONTENTS}

GLOSSARY

THE BELGIAN FINANCIAL SERVICES LANDSCAPE $\underline{7}$

ADDRESSING RECOMMENDATIONS IN THE 2006 FSAP $\underline{7}$

THE IMPACT OF CHANGES IN REGULATORY ARCHITECTURE $\underline{8}$

A. Background__ $\underline{8}$

B. The FSMA's Structure and Staff__ $\underline{11}$

C. Policy Development _ $\underline{12}$

D. General Supervisory Approach ___ $\underline{13}$

E. Conduct of Business Supervision __ $\underline{13}$

F. Prudential Supervision__ $\underline{14}$

G. Markets Supervision__ $\underline{16}$

H. Enforcement Activity __ $\underline{16}$

I. International Engagement__ $\underline{16}$

J. Cross-border Cooperation Arrangements___ $\underline{16}$

DESIGN OF THE REGULATORY MODEL ___ $\underline{16}$

COORDINATION AND COOPERATION BETWEEN THE FSMA AND THE NBB___ $\underline{\underline{\mathbf{1 7}}}$

STRUCTURED PRODUCT REGULATION__ $\underline{\underline{\mathbf{2 1}}}$

SYSTEMIC RISK AND REVIEWING THE REGULATORY PERIMETER___ $\underline{\mathbf{2 7}}$

CONCLUSION _

BOXES

1. The FSMA's Responsibilities __ $\underline{9}$

2. Prudential Supervision at the FSMA _ـ $\underline{15}$

3. Mandated Event and Institution Specific Interaction __ 18

4. Additional Areas to be Covered by Collaboration Protocols___ $\underline{20}$

5. Moratorium Elements__ $\underline{25}$ 


\section{FIGURE}

1. Exposure to Structured Products $\underline{22}$

\section{TABLES}

1. Detailed Policy Recommendations $\underline{3}$

2. Pre-Moratorium—Number and Value of Issuances by Year Since 2005 $\underline{22}$

3. Pre-Moratorium-Breakdown of Products by Product Type $\underline{23}$

4. Pre- Moratorium-Market Share of Key Institutions $\underline{23}$

\section{APPENDIXES}

I. Financial Services Institutions in Belgium Subject $\underline{30}$

II. Addressing Recommendations of the 2006 FSAP $\underline{32}$ 


\section{GLOSSARY}

BCBS

BCPS

CBFA

CRD

D-SIFI

EBA

ECB

EEA

EIOPA

ESMA

FSAP

FSB

FSMA

EC

EU

FC

FHC

FICOD

IAIS

ICPS

ICAAP

IOSCO

MiFID

NBB

RC

SIFI

SREP

UCIT
Basel Committee on Banking Supervision

Basel Core Principles for Effective Banking Supervision

Commission Bancaire, Financière et des Assurances

Capital Requirements Directive

Domestic Systemically Important Financial Institutions

European Banking Authority

European Central Bank

European Economic Area

European Insurance and Occupational Pensions Authority

European Securities and Markets Authority

Financial Sector Assessment Program

Financial Stability Board

Financial Services and Markets Authority

European Commission

The European Union

Financial Conglomerates

Financial Holding Company

FC Directive

International Association Insurance Supervisors

Insurance Core Principles

Internal Capital Adequacy Assessment Process

International Organization of Securities Commissions

Markets in Financial Instruments Directive

National Bank of Belgium

Risk Committee

Systemically Important Financial Institutions

Supervisory Review and Evaluation Process

Undertaking in collective investments in transferrable securities 


\section{THE BELGIAN FINANCIAL SERVICES LANDSCAPE ${ }^{1}$}

1. The Belgian securities market is dominated by a small number of banking groups which provide direct investment services and have investment fund affiliates. Despite its relatively small size, the Belgian market is serviced by a large number of small firms (many from other parts of Europe). Detail is set out in Appendix I.

\section{Activity in securities and financial services markets has remained subdued since the} crisis. Market capitalization has fallen from $€ 300$ billion in 2006 to $€ 212$ billion to the end of August 2012. Daily trading volume has risen from 25,000 per day in 2006 to over 60,000 per day since 2006, while the daily average value has fallen. The total net asset value of transferable securities (undertakings in collective investments in transferrable securities or UCIT) funds, fell dramatically from a peak of $€ 120$ billion in 2008 to $€ 79.5$ billion in 2012. This reflects poor market conditions with outflows accounting for only $€ 1.2$ billion of a decline of some $€ 12.5$ billion between the end of 2011 and mid 2012. Capital raising activity has also remained subdued, with 2 initial public offerings (IPOs) a year since 2009 and only six new listings in 2011.

\section{ADDRESSING RECOMMENDATIONS IN THE 2006 FSAP}

\section{The FSMA has generally addressed the recommendations made in the 2006 FSAP}

(Appendix II). This is explained, in part, by transposition of European Directives into Belgian law and, in part, by a number of initiatives taken since the restructure of the regulatory architecture in 2011. The FSMA should build on its work on product regulation, investor education and remain vigilant to the risks posed by unlisted issuers. The FSMA has made investor protection and education initiatives an early priority.

\section{Work toward a level playing field in the regulation of financial products should} continue. Despite initiatives taken to leveling, where possible, the playing field for UCITs, industry remains concerned about the cost impacts and arbitrage opportunities offered by differences in regulation between products but also between other European jurisdictions in relation to the same products. The FSMA should continue its active support of initiatives to level the product playing field at the European level and to extend the application of MiFID conduct requirements to the insurance sector. The FSMA has proposed legislation to give effect to this extension. The FSMA should not lose sight of the role supervision and surveillance play in ensuring a level playing field and to this end should extend its MiFID conduct supervisory programs to the insurance sector once that sector is subject to MiFID requirements.

\footnotetext{
${ }^{1}$ This note was prepared by Steven Bardy (Australia Securities and Investments Commission) during the FSAP update mission in November 2012. Mr. Bardy would like to thank Jean-Paul Servais and FSMA staff, in particular Jean-Michel Van Cottem and Hervé Dellicour, for their support and good humor in addressing his many (and often repeated) questions.
} 
5. Priority should be given to delivering planned investor education program. The FSMA has designed an impressive program which seeks to position the FSMA as a trusted source of information for consumers. The design of the program reflects international best practice and will focus on empowering and developing skills in consumers making investment and financial decisions. The FSMA should make execution of each of these plans a priority, drawing from the experiences and programs of other jurisdictions. Particular priority should be placed on publicizing the soon to be launched wikifin.be website to support investors in decision making. Plans to increase resources should be supported. The use of social media should also be integrated into these programs in order to spread the message to the younger, technology comfortable demographic that is the early target of the strategy.

\section{The FSMA should monitor issues associated with offerings by unlisted issuers. The} 2006 FSAP recommended that the Commission Bancaire, Financière et des Assurances (CBFA) be granted direct authority and undertake ongoing supervision of unlisted issuers, with particular concerns about the absence of disclosure requirements in relation to price sensitive information. This recommendation has not been acted on. Despite the FSMA monitoring unlisted issuers which make certain public offerings, we remain concerned that investors in these issues may not benefit from the same level of ongoing information available to investors in issues made by listed companies. The FSMA should continue to monitor any concerns and risks arising from the absence of these requirements.

\section{THE IMPACT OF CHANGES IN REGULATORY}

\section{ARCHITECTURE}

\section{A. Background}

7. Significant changes have taken place in regulatory architecture in Belgium in response to the crisis. In 2009 a special Parliamentary Committee was established to review the regulatory architecture, a review was similar to reviews in a number of other jurisdictions undertaken at the time. ${ }^{2}$ The review recommended the division of responsibility for supervision between the central bank (NBB) and the market conduct regulator (FSMA). The NBB was given responsibility for financial stability monitoring and prudential supervision of banks, insurance firms and stockbrokers. The FSMA was given responsibility for the regulation and supervision of financial markets, the conduct of market participants and investor protection and the micro prudential supervision of firms not supervised by the NBB. The new architecture was described in legislation passed in July 2010 (the

\footnotetext{
${ }^{2}$ In Europe, France, the U.K., Ireland, Lithuania, Portugal, Greece, Hungary undertook reviews. South Africa has also undertaken and is implementing a review. Before the Crisis, 14 of the $27 \mathrm{EU}$ countries had a single financial regulator (though organised in different ways), six followed a sectoral approach, three had an integrated sectoral model and three combined regulation by sector with regulation by objective with one (Netherlands) choosing a twin peaks model (Herring, R. and J. Carmassi (2008), 'The Structure of Cross-Sector Financial Supervision', Financial Markets, Institutions \& Instruments, 17(1), 51-76.))
} 
Law of 2010) with detail set out in a Royal Decree of March 3, 2011 (Royal Decree). The restructure took effect on April 1, 2011. The FSMA's responsibilities (and the objectives they are intended to achieve) are set out in Box 1.

\section{Box 1. The FSMA's Responsibilities}

The Law of 2010 and the 2011 Royal Decree gave the FSMA the following responsibilities:

- The supervision and surveillance of financial markets with the objective of ensuring fair and efficient operation of markets. The NBB was given responsibility for the oversight and prudential supervision of financial market infrastructure (FMI), and the FSMA for the supervision of compliance with rules of conduct which apply to FMI;

- The regulation and supervision of the conduct of all financial services markets participants and all financial services institutions (including those supervised by the NBB) with a clear objective to ensure the protection of consumers. ${ }^{1}$ This includes responsibility for financial products, the financial information distributed by listed companies and the detection of market abuse;

- The supervision of financial services firms not supervised by the NBB. The objective, as with other prudential supervision, is to ensure the following firms honor their financial commitments to customers: ${ }^{2}$

- Portfolio management and investment advice companies;

- Management companies of undertakings in collective investments in transferrable securities (UCITs);

$\circ$ Bureaux de change;

- Insurance and reinsurance intermediaries;

$\circ \quad$ Intermediaries in banking and investment services; and

- Supplementary pension schemes; ${ }^{3}$

- Contributing to the financial education of consumers and investors, and ensuring compliance with rules intended to protect consumers and investors against illegal offers and more generally in relation to the provision of financial products and services.

${ }^{1}$ The main source of conduct of business rules is the Law of 2002 which covers general conduct of business obligations, best execution and a general obligation to act honestly, fairly and 'in a manner which promotes the integrity of the market'.

${ }^{2}$ Prudential supervision includes responsibility for supervising capital and other prudential standards (including internal governance and organization and fit and proper assessments of management and shareholders).

${ }^{3}$ Consideration is being given to transferring responsibility for prudential supervision of these funds to the NBB. 


\section{The new structure reflects four key themes: ${ }^{3}$}

- Objective or outcome based (rather than functional or institution based) supervision. The NBB's responsibility is to safeguard financial stability, the FSMA's responsibilities relate to investor protection and markets;

- Responding to the difficulty of combining prudential and conduct of business regulation (which require different approaches and cultures) into the same organization. ${ }^{4}$ The new structure was seen as providing an opportunity to provide a greater focus on retail investors by generally separating responsibility for conduct and investor protection and education from prudential supervision;

- A clear division of responsibilities. The aim has been to avoid the duplication of tasks, the risk of conflicting decisions and regulatory arbitrage, minimizing opportunities for turf wars; ${ }^{5}$ and

- Clarity about which of the authorities prevail in the event of disagreement. The Royal Decree makes the regulator responsible for licensing an entity responsible for decisions affecting that entity. Financial stability or macro-prudential considerations are given priority over conduct of business, markets and prudential supervision considerations where they conflict. ${ }^{6}$ Provision is also made for resolving conflicts.

9. The FSMA has approached the challenges of the new arrangements with resolve. The FSMA treated the restructure as an opportunity to drive cultural change in a reinvented organization. Initiatives have focused heavily on investor education and protection. They promise an improvement in the quality and effectiveness of conduct regulation and investor protection in Belgium. The complex products "Moratorium," discussed in detail below, has used soft law solutions to drive outcomes which would have been difficult to achieve with legislation.

\footnotetext{
${ }^{3}$ The FSMA has indicated the philosophy of the reform was to align the Belgian model to the dominant models in Europe but also to capitalize on existing twin peak models abroad and, in particular, to avoid overlap of competences leading to unclear responsibilities or to conflicts between authorities.

${ }^{4}$ Note also comments in relation to the U.K. in HM Treasury, A New Approach to Financial Regulation - Judgement Focus and Stability July 2010, http://www.hm-treasury.gov.uk/consult fin regulation draft secondary leg.htm (HMT, 2011).

${ }^{5}$ These are also issues identified in the G30 Report, Financial Reform A Framework for Financial Stability. January 2009 http://www.group30.org/rpt 03.shtml

${ }^{6}$ This contrasts with the position in the U.K. where under proposed arrangements the Prudential Regulatory Authority (PRA) will have a veto to be exercised when regulators are unable to agree a course of action and the PRA is materially concerned that a proposed action by the Financial Conduct Authority (FCA) would lead to a disorderly failure of a firm or firms or wider systemic instability. The use of the veto power is intended to be limited and only subject to transparent safeguards (HMT, 2011).
} 


\section{As it moves to focus more on execution, the FSMA must ensure it has both the} resources and the same strong focus on driving key outcomes. The FSMA should ensure it continues to engage constructively and in a balanced way with consumer groups and industry in progressing its plans. The FSMA maintains ongoing dialogue with industry groupings and engages in informal consultation, including on costs and benefits.

11. The new regulatory architecture remains a work in progress. Further work is needed to ensure the model is the most effective and efficient way of achieving its objectives. The responsibilities vested in the FSMA point to the need for closer collaboration with the NBB. All NBB supervised institutions are subject to conduct regulation by the FSMA. A number of firms which are subject to exclusive supervision by the FSMA are part of groups subject to NBB consolidated supervision. A broad MOU on cooperation between NBB and FSMA came into effect in March 2013, supplementing already existing MOU in relation to FMIs. ${ }^{7}$ This will set the stage for further work in formalizing collaboration.

\section{Concerns also remain about the risk of regulatory arbitrage arising from differences in} regulatory and supervisory approaches between the NBB and the FSMA. Although there are few apparent arbitrage risks with the current division of responsibilities, the authorities should work together to monitor the emergence of arbitrage opportunities (possibly through industry and market innovation and through differences in approach to supervision and regulation).

\section{B. The FSMA's Structure and Staff}

13. The FSMA restructured its operations in mid-2011 to reflect the objectives of the new model. Rather than organizing activity by type of regulated institution (as under the CBFA), the FSMA was organized around regulatory focus. New departments were created to deliver new responsibilities. ${ }^{8}$ Conduct regulation and investor protection departments were established. A Policy Department was also created centralizing strategic policy work, creating potential to develop securities and financial services policy expertise, assess key organizational priorities and provide the Management Committee with important strategic support.

\footnotetext{
${ }^{7}$ Following the FSAP mission, a general MOU on collaboration between the NBB and the FSMA to ensure coordination of the supervision of institutions under the respective supervision of the two agencies has been concluded on March 14, 2013. See http://www.fsma.be/en/About\%20FSMA/mou/samenwerkingsaccord.aspx.

${ }^{8}$ In respects other than those listed in the text, the management structure of the FSMA was the same as for the CBFA (with two fewer members of the Management Committee and the establishment of an Audit Committee).
} 
14. The FSMA embarked, more generally, on a program to recruit new staff with 22 external hires with a new range of skills recruited. ${ }^{9}$ The FSMA's funding model, which continues funding by regulated firms, has also ensured the FSMA has access to sufficient resources to staff new programs. The FSMA currently has a complement of over 250 staff with provision to increase the number to over 311 by 2015.

15. Industry and consumer groups have seen a change in culture. The FSMA is now seen by those it regulates as more open, proactive, constructive and engaging. At the same time, and despite organizational upheaval, the FSMA has maintained the same high level of service in its legacy operations.

\section{Policy Development}

\section{The FSMA's early policy work has emphasized investor protection through a range of initiatives:}

- Complex structured products. The FSMA has responded creatively to the regulatory challenges posed by complex structured products by agreeing a Moratorium on the distribution of these products with industry (Structured Products section below). ${ }^{10}$

- Savings accounts. Savings accounts are the most popular investment in Belgium with households investing $€ 210$ billion in these accounts. ${ }^{11}$ The FSMA has worked with industry to improve product features and is drafting standards to ensure consistent implementation of standards by all banks. The FSMA, in consultation with industry, has also developed a standard information document intended to create both clarity and the opportunity for investors to compare products. Legislation has also been drafted about advertising these products.

- Joint offers. The FSMA has issued guidance which discourages 'joint offers' of financial products with non-financial products. This is intended to ensure consumers' attention is drawn to the financial product and its advantages, rather than to other goods.

- Compliance officers. The FSMA has published draft regulations about the role and competencies of compliance officers in regulated firms. Under the regulation compliance officers would be required to monitor and evaluate the adequacy and effectiveness of their firm's policy,

procedures and measures to ensure compliance. Compliance officers would be registered by the FSMA and must meet training, experience and knowledge requirements. The FSMA should work

\footnotetext{
${ }^{9}$ As at November 2012.

10 Structured products are defined by the Moratorium, described below, as investment products sold either as notes, UCITS insurance products or deposits that include a derivative component with the 'repayment or yield depending on the performance of one or more underlyings on the basis of a formula.

${ }^{11}$ These are in addition to the simulator being developed as part of its investor education strategy. See discussion under Investor Education initiatives.
} 
to ensure that the approval process is both meaningful and ensures the quality of the compliance profession in Belgium is raised.

17. Other important work is in the pipeline. Initiatives include developing labeling systems for financial products (irrespective of wrapper) covering risk to principal, whether the return is fixed or variable and whether the product is complex or not. Mystery shopping programs and licensing of financial planners are also being considered. The regulation of financial planners is also an important initiative. It will extend the regulatory net to a group of firms which, while not holding client assets or executing client instructions, are able to influence the decisions their clients make. They should, for that reason, be regulated similarly to other intermediaries. The FSMA should give these programs priority.

\section{General Supervisory Approach}

18. The FSMA is adopting a new approach to supervision with a particular focus on areas with high customer impact. The FSMA has designed a new program to supervise MiFID conduct of business requirements. Adequate resourcing and a focus on key objectives will be important considerations in the effective execution of this program. The FSMA should also not lose sight of the need for vigilant prudential oversight of those firms for which it is the sole regulator.

\section{E. Conduct of Business Supervision}

\section{The FSMA's initial focus has been on conduct of business requirements under MiFID.}

The FSMA established a new team in mid-2011 to develop and implement a standalone program to supervise conduct of the 183 firms in Belgium subject to these requirements, broadening the program from the CBFA's focus on large firms. External consultants drawn from large audit firms were engaged to assist in designing a supervision process for firms subject to MiFID requirements. ${ }^{12}$ The process will be rolled out in late 2012 and early 2013. Properly executed, the program will contribute to the credibility of the FSMA as an effective supervisor.

\section{The FSMA faces three execution challenges:}

- Resourcing. The FSMA should ensure it has the right number and type of resources to adequately supervise the full population subject to MiFID requirements. In particular, it should ensure that the program involves on-site visits with a frequency and intensity consistent with its assessment of risks posed to investors and consumers. The FSMA is considering supplementing its resources with use of audit firms for on-site visits. Although this may address resource pressures, the FSMA will need to take steps to ensure the quality of audits meets the same standards set for audits conducted by FSMA officers;

\footnotetext{
12 Insurance intermediaries are not included as they are not currently captured by MiFID conduct of business requirements. With an extension of these requirements to insurance firms, consideration will be given to extending this program to insurance intermediaries. Other intermediaries are also not directly covered.
} 
- Rigor in Risk Assessment. It is unclear how data collected by the FSMA through the survey mapping process it describes as the "cartographie" will be used to assess the content of thematic reviews and identifying targets for supervision. Introducing rigor and transparency into these processes should be a priority; and

- Avoiding a 'tick the box' exercise. The FSMA should ensure in-field auditors or supervisors apply the processes with some judgment and understanding of the broader context, particularly if external auditors are engaged to undertake audits. The temptation might be to rely on the comfort of a rigorous and regimented process to replace reflection when meeting tight deadlines.

\section{The FSMA should ensure the program assesses compliance with MiFID requirements} regarding intermediary agreements with customers. The 2006 FSAP noted the absence of these requirements in Belgium. As set out in Appendix II, although these requirements were introduced into Belgian law in 2007, the FSMA is unclear about industry compliance. Compliance with these requirements. Issues such as simplicity, completeness and accessibility of these agreements should be addressed to ensure their value is maximized. They are a fundamental tool for investors to access and understand their rights.

\section{The FSMA has been active in supervising firms while developing the new audit}

program. The FSMA undertook supervision on a "test basis" during 2012. By the end of 2012, 26 assignments were to have been conducted. These include 18 short assignments (which have involved high level discussions of the MiFID themes) and 8 long assignments (currently under way) exploring approaches to conflicts of interest. Short assignments were divided evenly between credit institutions and investment firms. Long assignments focused more on credit institutions (with 6 credit institutions visited and 2 investment firms visited). Only one UCITS management company was visited during the year.

23. Programs to supervise the conduct of other intermediaries are also in place. The FSMA has also visited banks testing compliance with obligations about conduct to clients. ${ }^{13}$ Roughly 10 percent of a population in the order of 4,000 has been inspected by both the CBFA and the FSMA in recent years, with at least 50 percent of inspections resulting in the intermediary being removed from the register (because they no longer satisfy basic requirements). The high level of noncompliance points to the need for more intense supervision of these intermediaries.

\section{F. Prudential Supervision ${ }^{14}$}

24. The focus of prudential supervision has not changed significantly since the restructure. Supervision continues to be a mix of desk based analysis of documents lodged with the FSMA and on site visits. The key change is the separation of this supervision from conduct of business

\footnotetext{
${ }^{13}$ Article 14 of the Law of 22 March 2006.
} 
supervision. The intensity and nature of supervision varies according to institution type with a heavier reliance on continuous desk based research and a relatively light program of on-site visits (Box 2).

\section{Box 2. Prudential Supervision at the FSMA}

The supervision of collective investment management companies is undertaken through a mix of desk based reviews and on-site visits. Desk-based reviews include reviews of documents lodged by the Collective Investment Scheme (CIS) management company (including notification of changes in capital structure and key changes in the organization and governance of the CIS) and reports of accredited auditors about the organization of the CIS. The reviews are undertaken on a continuous basis.

Depositories are responsible for oversight of CIS activities and monitoring asset eligibility, net asset value (NAV), the execution of subscription and redemption orders and compliance with investment restrictions. Accredited auditors undertake annual audits of the financial accounts of CIS and report on the appropriateness of the organization and structure of the CIS. They are also required to report to the FSMA on events which may have a significant impact on the CIS.

FSMA on-site visits are undertaken with a view to ensuring compliance and investigating suspected breaches. There have been only 9 visits between 2007 and 2011 and 3 in 2012. The focus of recent visits was on the pricing of derivatives and global risk limits as well as the analysis of the governance of the institution

Portfolio management and investment advice companies are also subject to risk-based desk and on-site audits. Given the small population, every firm can expect to have its lodgments reviewed. Fewer firms are subject to an on-site review, with a single staff member dedicated to these audits.

Banking services brokers (which must meet minimal financial requirements and some organizational requirements) are subject to desk checks used to assess whether registration conditions are being met. ${ }^{15}$ The purpose of this supervision is to ensure that brokers (both firms and individuals) are able to meet all of their obligations at all times and can guarantee the continuity of their businesses. The FSMA has indicated that this supervision is conducted on a risk basis—rather than a routine basis.

The focus on intermediaries and mortgage credit institutions in recent years has also been on supervising compliance and responding to non-compliance with legal conditions on registration. Mortgage credit institutions are subject to on-site inspections which focus on particular thematic issues in a given year.

25. The intensity and design of prudential supervision should be kept under review. The intensity of supervision of these firms appears appropriate, with key financial risks being addressed through desk research. The number of on-site visits, however, appears to be low with scope for review.

\footnotetext{
${ }^{14}$ As is the case for many other conduct regulators, the FSMA has responsibility for supervising ongoing capital and other prudential requirements for firms not prudentially regulated by the NBB. By ensuring these firms maintain financial resources sufficient to meet business commitments and to withstand the risks these firms face, these prudential style requirements contribute to the protection of investors and the integrity and stability of financial markets (IOSCO Principles 28 and 30). Supervision of these requirements continues to be a mix of desk based analysis of documents lodged with the FSMA. They key change is separation of this supervision from conduct of business supervision. The intensity and nature of supervision varies according to institution type with a heavier reliance on continuous desk based research and a relatively light program of on-site visits (Box 2).

${ }^{15}$ Bank intermediaries which work under the aegis of banks are not subject to financial or organisational requirements
} 


\section{G. Markets Supervision}

26. The FSMA has continued the former CBFA's approach to the supervision of listed companies and markets. The FSMA has implemented European directives on short selling and transparency. The FSMA is also responsible for the Securities Regulation Fund in charge of the detection of market abuse and the production of statistics on trading volumes on the secondary market of public debt securities.

\section{H. Enforcement Activity}

27. The FSMA remains vigilant in taking action using new procedures including for administrative fines. These procedures are intended to improve the efficiency and transparency of the investigation and enforcement process and so enhance the deterrence impact of the FSMA's activity. Under the new procedures, during 2011, investigations officers submitted 12 investigation reports to the Management Committee relating to 24 individuals or legal entities. Eighteen of these related to insider dealing, five to non-compliance with issuer requirements to disclose inside information and market manipulation and one in relation specifically to market manipulation.

\section{International Engagement}

28. The FSMA actively contributes to the work of both European and international organizations. At the international level, the FSMA has contributed to the work of IOSCO Committees on Accounting, Audit and Disclosure and Investment Management. It has also been a significant contributor to the work of the IOSCO Task Force exploring regulatory approaches to Retail Structured Products. At the European level, the FSMA chairs ESMA's permanent working group on Investor Protection and Intermediaries and has contributed to the work on financial innovation and implementation of the Alternative Investment Fund Managers Directive.

\section{J. Cross-border Cooperation Arrangements}

29. The increasing role of foreign firms in the Belgian markets underscores the importance of effective cooperation agreements. Agreements, which remain in place, were assessed as being sufficient in the 2006 FSAP. Cooperation with regulators in other jurisdictions appears to continue to be timely and efficient. Requests in market abuse cases are responded to, on average, within 40 days of the request being made.

\section{DESIGN OF THE REGULATORY MODEL}

30. The division of responsibility between the NBB and the FSMA is clear to industry and the markets. Feedback from industry and discussions with the NBB and the FSMA points to the division of responsibilities being clear and well understood. The FSMA does not have responsibility for the prudential supervision of stock broking firms (as will be the case for most firms in the U.K. and is the case in Australia). Supervisory responsibility has been allocated to the NBB based on the 
view that stock brokers are similar to investment banks and hold client assets, therefore posing greater investor and market risks than investment firms which do not. ${ }^{16}$ Synergies with the supervision by the FSMA of other investment firms may be greater than the synergies with supervision of insurance firms and banks by the NBB. On balance, however, responsibility for supervision of stock broking firms should not be moved. Current arrangements should be given the chance to work with an assessment at a later stage.

31. Arbitrage risks are low but should be monitored. There are not enough differences in the prudential supervisory approach of the NBB and the FSMA to create incentives to seek to arbitrage the two authorities. It would also be difficult for businesses supervised by the NBB to restructure their operations and business models in a way that would bring them under the purview of the FSMA. There is a risk that differences in approach to prudential supervision over time may create such incentives. The FSMA should work with the NBB to ensure consistency of approach to supervision of intermediaries, in particular, and monitor arbitrage risks.

\section{COORDINATION AND COOPERATION BETWEEN THE} FSMA AND THE NBB

\section{Effective and meaningful cooperation between the FSMA and the NBB is critical to the} success of the new institutional design. The significance of co-ordination and co-operation is recognized in legislation setting up the regulatory structure. The Royal Decree sets out in some detail how the NBB and the FSMA should work together in relation to specific events and institutions. Amendments were made to the organic law of both institutions and to sectoral law to give effect to these changes (Box 3).

\footnotetext{
${ }^{16}$ The NBB also has responsibility for Anti-Money Laundering legislation (again in contrast to the position in other jurisdictions where this is the responsibility either of a standalone institution or the conduct regulator). Given the FSMA is responsible for the supervision of bureaux de change this division of responsibilities reemphasizes the need for close cooperation between the NBB and the FSMA.
} 


\section{Box 3. Mandated Event and Institution Specific Interaction}

Fit and proper assessments. The NBB is required to consult with the FSMA in assessing the professional integrity of directors and persons nominated to participate in the 'effective center of management' of a financial institution supervised by the NBB. ${ }^{1}$ The NBB is not bound by the FSMA's opinion. There are similar provisions which apply in relation to institutions under the exclusive supervision of the FSMA.

Consultation and collaboration on licensing. In the case of banks, the NBB is required to seek the FSMA's opinion on a range of matters within the FSMA's competence (including assessments of the professional standing of persons, the adequacy of the firm's integrity policy its track record in treatment of customers and the independence and adequacy of its compliance function. ${ }^{2}$ The NBB is again not bound by the FSMA's views but, if it disagrees, must publish its reasons for not agreeing. Similar provisions are in place in other sectors and are mirrored in decisions the FSMA is required to take about the firms it licenses. ${ }^{3}$

Enforcement Activity. The FSMA and the NBB must consult in relation to enforcement activity against entities under the prudential supervision of the NBB. The FSMA is required to inform and collaborate with the NBB and the NBB is given the opportunity to oppose measures (ranging from action to prohibit the offer of certain services through revocation of the license of a firm) but only on the basis of threats to financial stability. A process for arbitrating differences where agreement on action cannot be reached is also set out.

${ }^{1}$ Article 26bis of the Law of 22 March 1993 on Supervision of Credit Institutions and Article 116 of the Royal Decree.

${ }^{2}$ Articles 8 and 9 of the 1993 Law on Supervision of Credit Institutions.

${ }^{3}$ Relevant provisions under other sectoral laws include Chapter 11 of the Law of 9 July 1975 on insurance Enterprises, Article 48 and 49 of the Law of 6 April on Supervision of Investment Companies and Articles 250 to 253 of the Law of 20 July 2004 on Collective Investment Portfolio Management.

\section{While recognizing the responsibilities of the two authorities, the NBB's financial} stability objective is given primacy. The Law of 2010, also makes it clear that the FSMA's supervision should not prejudice the exercise by the NBB of its powers and competencies. ${ }^{17}$ The FSMA has the power to suspend or prohibit the exercise of all or part of the activities of an undertaking that is also subject to NBB prudential supervision. In that process, the FSMA is required to inform the NBB of the measures it intends to take. The NBB can oppose the measures proposed on financial stability grounds. ${ }^{18}$ At the request of the NBB, the FSMA must also provide the NBB with relevant information about systemic institutions, to support the Bank achieving its objectives. ${ }^{19}$

\section{The NBB and the FSMA collaborate in a number of areas on a formal and an informal}

basis. There is evidence of co-operation on an informal basis. The Governor of the NBB and the Chairman of the FSMA and Management Committees of the two organizations meet regularly to discuss issues of mutual relevance and interest. Information has also been shared at an operational level, for instance, in the context of developing the MiFID conduct audit process. There is also anecdotal evidence of information being shared in the context of supervisory visits; although this is informal. Information has been shared in relation to enforcement proceedings and the authorities

\footnotetext{
${ }^{17}$ Article 33 of the Law of 2002.

${ }^{18}$ Article 36 bis of the Law of 2002.

${ }^{19}$ Article 36/3 paragraph 6 of the Law of 22 February 1998 establishing the NBB's Charter.
} 
cooperate as contemplated by the Law on licensing matters. There are also recent examples of cooperation between the FSMA and NBB coordinating policy developments for the financial sector in Belgium. An example is work between the two in developing guidance on the role of the compliance function.

\section{Amendments are proposed to clarify the FSMA's obligations to share information with} the NBB for purposes of prudential supervision. These amendments will be important to to ensure that the NBB has all the information necessary to monitor and understand risks to financial stability. A key feature of the crisis was the role product design and marketing played in triggering the collapse of significant financial institutions. This was compounded by the failure of supervisors to share information and together understand the impact practices in markets may have on the soundness of prudentially regulated institutions and the broader economy. As some have noted, problems in conduct of business are often precursors of prudential difficulties. It is encouraging that the Belgian authorities are considering the establishment of a Macro Prudential Regulation Council, paralleling initiatives in other jurisdictions. ${ }^{20}$

\section{The NBB is not required to share information with the FSMA to support the FSMA's} mission. Consideration should be given to introducing such a provision to supplement other cooperation described above and in Box 3. It will, for instance, be useful for the FSMA to be aware of failures or weaknesses in an institution's capital, liquidity or governance structure which may create incentives for firms within the institution's group to engage in misselling practices.

37. The new MOU will set the stage for completing the formalization. The new agreement of March 2013 covers the sharing of information provided to authorities by regulated firms. At present, both authorities receive information (in some cases from the same institutions and firms) which may be relevant to the other. The Protocol is intended to avoid duplication of reporting and allow the FSMA to access existing periodic prudential reporting collected by the NBB for use in its own supervisory activities. It will also support a legal obligation (in place since April 2012) for both to share financial and non-financial information necessary for the execution of their legislated missions. A protocol for cooperation in monitoring and supervising FMIs (including Euroclear and $\mathrm{LCH}$ Clearnet) is also in place.

\section{Collaboration Protocols will support industry confidence in the institutional} arrangements for regulation. The Protocols would also support each Authority in the exercise of its powers within the limits of its regulatory mandate and support-rather than hinder-the efficient operation of the supervisory architecture. Areas which could be covered by the Coordination Protocols are set out in Box 4.

\footnotetext{
${ }^{20}$ This initiative compares with U.K. proposals (HMT, February 2011, Chapter 2) and the Australian Council for Financial Regulators.
} 


\section{Box 4. Additional Areas to be Covered by Collaboration Protocols}

\section{Sharing Intelligence}

Provision could be made in future Collaboration Protocols for sharing intelligence on an 'as needs' basis. . Each authority will look at many of the same institutions and firms through different lenses - and assess priorities and concerns influenced by that lens. The sharing of information, assessments and analyses allow both to more fully and completely execute their primary responsibilities and identify gaps, overlaps and arbitrage risks.

\section{Policy Development}

Collaboration Protocols could address consultation on proposed changes in regulatory policy, guidance or other regulatory decisions which impact on the responsibilities of the other; and consultation on the timing of implementation of policy changes impacting the responsibilities of the other. Consideration could be given to issuing joint policy and consultation documents.

\section{Supervision}

Formal cooperation between the NBB and the FSMA in the design and conduct of supervision and surveillance activity of jointly supervised entities would enhance the efficient operation of current arrangements. It is unclear whether current arrangements leave gaps in supervision. For instance, on the assumption that the NBB focuses on capital, governance and risk management issues as they impact on prudential outcomes for the entities it regulates, it is not clear whether the FSMA, where it also regulates a particular entity, focuses on other aspects of risk management and governance and whether it coordinates with and shares experiences with the NBB.

Consideration could be given to the developing a forward program for supervising jointly regulated firms and entities. This will, at the very least, address the risks of coinciding visits and ideally encourage the conduct of joint activity or activity where one delegates to the other (as is the case in Austria, Italy and Spain); and constructing joint data bases housing information relevant to both agencies to which both have access. This would assist in ensuring firms are only asked for information once.

\section{Investigation and Enforcement}

Collaboration Protocols should also address co-operation in the conduct of investigations and taking enforcement action. Consideration should be given, for instance, to requiring the NBB and the FSMA to actively co-operate at an earlier stage of investigations around decisions about whether to investigate and take action in relation to firms which are regulated by both. This would build on existing obligations on the FSMA to inform the NBB of any alleged breaches of conduct of business rules by NBB regulated institutions and the actions it proposes to take. It would also supplement the NBB's power to oppose specific sanctions that the FSMA may want to impose on firms in relation to breaches of conduct of business rules.

\section{International Cooperation}

The Protocols could address how the authorities will coordinate their engagement internationally. This may address issues such as the FSMA's representation at the International Association of Insurance Supervisors in relation to matters affecting insurance intermediaries and conduct of business. 


\section{Collaboration Protocols should be supported by liaison arrangements between the} authorities at a number of levels. This will breathe life into the commitments both institutions make in the protocols. Key elements which could be considered include the following:

- Formal meetings at a fixed frequency between the Governor/Chairman and Management Committee/Board level;

- A cross authority liaison committee at operational level to meet on a regular basis as a forum for discussing operational matters between the authorities. This could be used to identify policy projects and surveillance activity of interest to the other authority and a forum for monitoring progress and issues faced in joint activity (or activity covering similar firms);

- A liaison committee dedicated to investigation and enforcement activity should be established. This group should meet regularly and discuss operational aspects of investigation matters; and

- Each agency should appoint a liaison officer to act as the primary point of contact between the two authorities at operational level.

40. Other measures could be considered to improve coordination and co-operation. For instance, the authorities could be required to have regard to each others' objectives. This would ensure that both authorities would have each other's interests in mind when making regulatory and supervisory decisions and considering new policy. Consideration might also be given to Management Committees participating in relevant parts of each others' meetings, enhancing cooperation at the most senior levels of both organizations and for leaders to discuss issues of common and joint interest. Both authorities could also be required to report annually about how they co-operate and coordinate. Similar measures are in place in both France and the Netherlands.

\section{STRUCTURED PRODUCT REGULATION}

41. The FSMA has responded creatively to the regulatory challenges posed by complex structured products by agreeing a "Moratorium" on distribution of these products with industry. Retail structured products pose misselling and information asymmetry risks to investors. To address these risks, the FSMA has taken a more interventionist and innovative approach which looks beyond the point of sale across the value chain.

42. Structured products are a significant feature of retail investment offerings in Belgium. At the end of 2011 they accounted for $€ 83$ billion measured by amount outstanding. The market is one of the largest in Europe in absolute terms. Belgium also has significantly higher per capita exposure to structured retail products (SRPs) than any other market in Europe. The popularity of these products reflects, in part, a desire for investors to combine security (offered by capital guarantees associated with these products) with the return potential offered by a range of underlying assets. It is an investor appetite which the competitive banking market place of the last decade exploited effectively. 


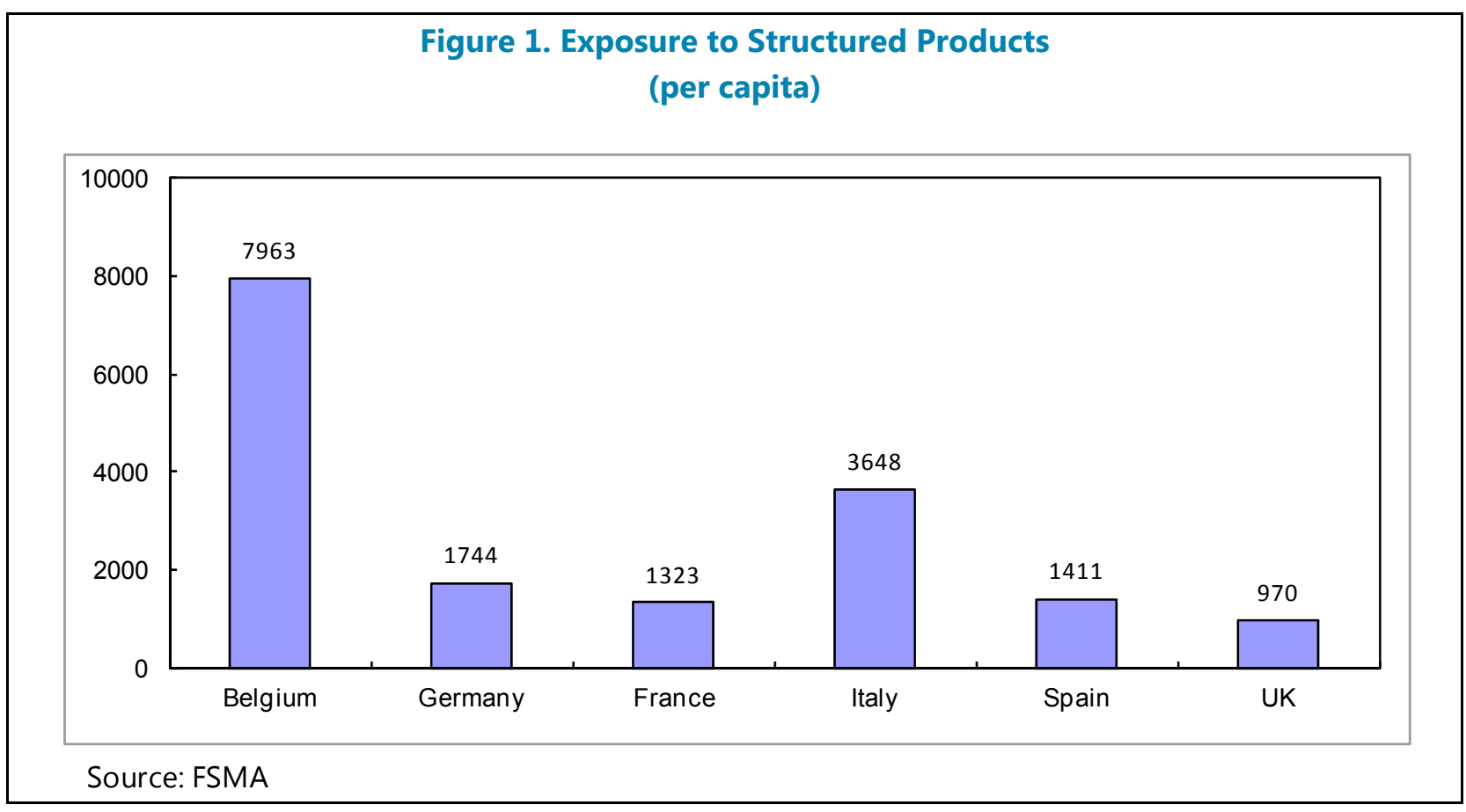

43. The market has contracted since the crisis. The number and value of issuances have fallen by 20 percent with average issue size dropping (Table 2).

Table 2. Pre-Moratorium—Number and Value of Issuances by Year Since 2005

\begin{tabular}{|c|c|c|c|c|c|c|c|}
\hline & 2005 & 2006 & 2007 & 2008 & 2009 & 2010 & $\begin{array}{c}2011 \\
\text { (to July ) }\end{array}$ \\
\hline $\begin{array}{l}\text { Number of } \\
\text { issuances }\end{array}$ & 456 & 472 & 597 & 543 & 431 & 504 & 285 \\
\hline $\begin{array}{l}\text { Value of issuance } \\
\text { (€ billion) }\end{array}$ & 19,044 & 17,422 & 18,603 & 11,989 & 9,628 & 9,704 & 4,486 \\
\hline $\begin{array}{l}\text { Outstanding } \\
\text { amount ( } € \text { billion)* }\end{array}$ & & & & 86,151 & 85,212 & 86,676 & 82,772 \\
\hline
\end{tabular}

*Figures only available from 2008.

Source: www.structuredretailproducts.com. 


\section{There have also been significant changes in the wrappers under which products are}

sold. Until 2011, structured products were sold primarily as funds or notes but there has been a shift to products sold under an insurance wrapper, reflecting the cost advantages of the insurance wrapper (with fewer compliance requirements to get to market) (Table 3). Features have remained similar-with capital protection remaining a key feature. Issuance and distribution has been dominated by the Big 4 Banks (Table 4).

\begin{tabular}{|c|c|c|c|c|c|c|c|}
\hline \multicolumn{8}{|c|}{$\begin{aligned} \text { Table 3. Pre-Moratorium-Breakdown of Products by Product Type } \\
\text { (euro billion) }\end{aligned}$} \\
\hline & 2005 & 2006 & 2007 & 2008 & 2009 & 2010 & 2011 \\
\hline Funds & 13,135 & 11,443 & 13,261 & 6,376 & 5,332 & 5,339 & 2,572 \\
\hline Notes & 4,710 & 4,754 & 3,959 & 4,165 & 3,463 & 3,423 & 2,477 \\
\hline $\begin{array}{l}\text { Insurance } \\
\text { Product }\end{array}$ & 1,200 & 1,224 & 1,383 & 1,447 & 0,821 & 0,901 & 1,796 \\
\hline Deposits & 0 & 0 & 0 & 0 & 0 & 0,041 & 0,114 \\
\hline Total & 19,044 & 17,422 & 18,603 & 11,989 & 9,616 & 9,701 & 7,062 \\
\hline
\end{tabular}

Table 4. Pre- Moratorium-Market Share of Key Institutions

(in percent)

\begin{tabular}{llllllll}
\hline & $\mathbf{2 0 0 5}$ & $\mathbf{2 0 0 6}$ & $\mathbf{2 0 0 7}$ & $\mathbf{2 0 0 8}$ & $\mathbf{2 0 0 9}$ & $\mathbf{2 0 1 0}$ & $\mathbf{2 0 1 1}$ \\
\hline KBC & 33 & 32 & 43 & 41 & 39 & 48 & 52 \\
ING & 15 & 13 & 8 & 7 & 17 & 14 & 15 \\
BNP Paribas & 26 & 24 & 23 & 13 & 14 & 11 & 6 \\
$\begin{array}{l}\text { Fortis } \\
\text { Dexia/Belfius }\end{array}$ & 7 & 8 & 4 & 17 & 9 & 5 & 6 \\
\hline
\end{tabular}

Source: www.structuredretailproduct.com. 
45. Regulation is focused on disclosure and intermediary conduct. The Belgian regulatory framework focuses heavily on disclosure and conduct regulation at the point-of-sale with preapproval of point of sale disclosure documents and marketing materials effectively giving the FSMA some early intervention powers. Regulation is set out in Belgian law (including transpositions of European Directives) supported by Royal Decrees and FSMA guidance. Examples of the latter include guidance on advertising, dossiers relating to public offerings and admissions to trading of bonds and other instruments on a regulated market and the public offer of corporate bonds.

\section{The Moratorium on complex structured products was a response to the Belgian}

experience of the crisis. In its report to the Belgian Parliament in April 2009, the Special Committee tasked with investigating the financial and banking crisis recommended that the 'traceability' of financial products be improved. The recommendation reflected concerns about the significant losses experienced by Belgian investors with the collapse of Lehmann brothers and with it the failure to honor obligations under mini-bonds marketed primarily through Citibank. Reports point to 17,000 investors suffering losses in the order of $€ 300$ million.

47. The FSMA acted quickly to exercise new powers. The Law of July 2, 2010 conferred on the then CBFA the power to impose bans or conditions on trading in retail investment products, including conditions intended to enhance the transparency in how products are priced. As one of its first initiatives, the FSMA undertook a review to consider how these powers could be exercised in relation to complex structured products, particularly those which were unsuitable for the average retail investor. This was done, in part, because of the size and significance of the retail structured products market in Belgium and, in part, in recognition of the fact that transparency and rules of conduct at the point of sale alone may not be sufficient to address the risks to investors posed by these products. Similar concerns have been expressed and addressed in other jurisdictions. ${ }^{21}$

48. After the Belgian experience of the crisis, a 'soft law' approach was preferred. The FSMA sought an agreeemnt with industry under which issuers and distributors would voluntarily refrain from distributing complex structured products for a defined period. The initiative (the Moratorium) was launched in June 2011 and entered into force on 1 August 2011. The FSMA indicated to industry that it would use the Moratorium to work with them to develop rules which it would put in place once the Moratorium expired (expected within six months). At the time of the mission, the Moratorium was still in place with no immediate plans to move to a 'hard law' approach through regulations and legislation.

\footnotetext{
${ }^{21}$ Other jurisdictions acted similarly to address risks to investors entailed in these products, albeit by different means. See in particular the United Kingdom (FSA "Discussion Paper 11/1 Product Intervention"), France (position of the AMF dated October 15, 2010 concerning the distribution of complex financial instruments), Italy (CONSOB notice no 9019104 of March 2, 2009 on "the intermediary's duty of correct and transparent conduct in the distribution of illiquid financial products"), the United States ("Investor alert" by the SEC and FINRA of June 2, 2011 on structured notes with principal protection) and Denmark ("Executive Order no. 345 dated April 15, 2011 on risk labeling of investment products").
} 


\section{The key objectives of the Moratorium were expressed as:}

- Helping consumers gain greater insight into the choices facing them;

- Enhancing the comparability of products and fostering competition; and

- Strengthening confidence of financial institutions in the proper functioning of the financial markets.

The Moratorium also provided an opportunity for regulatory intervention at a point earlier than the point-of-sale. The elements of the Moratorium were intended to encourage a greater focus on the needs of the investor at the product design stage (Box 5).

\section{Box 5. Moratorium Elements}

The Moratorium is expressed to apply to the distribution to retail investors of structured products that are considered particularly complex irrespective of the wrapper under which the product is sold. The Moratorium defines a number of key terms to ensure broad application:

- 'Structured products' are defined broadly to cover any investment product, whatever the wrapper form, including a derivative component the repayment or yield on which depends on the performance of one or more of the underlyings on the basis of a formula;

- 'Distribution' is defined broadly to cover different stages of the distribution process, including advertising and advice to urge customers to accept the product;

- 'Distributors' are deemed to include a broad range of institutions that distribute the relevant products including the issuer of the product; and

- The Moratorium was also expressed to cover all structured products distributed by the distributors and the group of which the distributor is a member. Limited carve outs apply to products sold to investors who hold deposits in excess of $€ 500,000$ with the distributor seeking to take advantage of the carve out and then only in relation to the amount above the threshold.

Documentation issued by the FSMA about the Moratorium encourages distributors to make reference to the Moratorium in their offer documents. Where the FSMA identifies non-compliance with the Moratorium by a distributor, their name is removed from a public register on which Moratorium signatories' names appear.

The pivotal concept of the Moratorium is the definition of 'particularly complex' structured products. The FSMA has provided useful guidance on how this should be addressed based on 'particularly complex' using the answers to 4 questions (with guidance on each being provided). The answers determine whether a product is to be treated as particularly complex (and as such, subject to the Moratorium). The questions are:

- Is the underlying value accessible (if no, the product is particularly complex)? This focuses on whether information about the underlying assets can be accessed easily by retail investors. Hedge funds and credit default swaps (CDS) are, for instance, deemed not to be accessible. In-house indices are generally not regarded as accessible;

- Is the strategy overly complex (if yes, the product is particularly complex)? This focuses on whether the value of the product can be accessed in a fair way. It has been interpreted very broadly and includes complexity derived from the way in which the product is marketed;

- Is the product subject to an overly complex calculation formula (if yes, the product is particularly complex)?; and

- Is there transparency regarding costs, credit risk and market value (if no, the product is particularly complex)? 
50. Most firms signed up to the Moratorium, citing the reputational risks to their business and brand by not doing so. Firms generally also saw the Moratorium as an important way of restoring confidence in the market. Since the Moratorium, 324 SRPs have been launched (of which 225 have been issued to retail investors and a further 79 to those satisfying the carve-out criterion (i.e., those holding deposits in excess of $€ 500,000)$ ).

\section{The Moratorium appears to have had the following effects:}

- A simplification of products on offer to the retail market since 2011;

- Products regarded by consumer groups and advisors as dangerously complex are no longer marketed to retail investors (although available to those investors in the carve-out). Reverse convertibles $^{22}$ and autocallables, where the tail risk in a product sold as conditionally capital guaranteed is borne by the investor, are no longer available to retail customers (although some are sold through the opt out). Teaser products, ${ }^{23}$ knock outs $^{24}$ and certain digitals ${ }^{25}$ are also no longer available to retail investors;

- Other products which do not meet the FSMA's guidelines can now only be sold to the limited group of investors in the carve-out. Issuers have in some cases rethought the design and distribution of their products to target investors in the carve-out; and

- A general improvement in product transparency facilitating improved comparability.

\section{Consumer groups and the advisory community are enthusiastic in their praise of the} Moratorium. They see the soft law approach as having given the FSMA the flexibility to adapt and respond to innovations as they happen. Industry is less enthusiastic, but admits improvements in transparency and a simpler products range. The Moratorium is generally seen as having improved the profile and credibility of the FSMA as a regulator committed to protecting investors.

\section{A major challenge for the FSMA is whether to continue the Moratorium or revert to a} 'hard law' approach based on legislation and regulation. In the middle of 2011, the FSMA launched a consultation on the adoption of a binding regulation relating to structured products. The

\footnotetext{
${ }^{22}$ These products typically offer a high fixed level of income and full return of capital unless a reference underlying asset of index falls over the term of the investment. If the underlying does fall in value the investor has their capital return reduced by the percentage fall in the value of the underlying (definition sourced from the www.structuredretailproducts.com glossary).

${ }^{23}$ These are products sold on the basis of offering a fixed return - but through only part - and an early part - of the product's life.

${ }^{24}$ These are products where the return is dependent on the underlying reaching-or not reaching - a pre-specified level at some time during the term of the investment, (Definition sourced from the www.structuredretailproducts.com glossary).

${ }^{25}$ These are products which pay a fixed amount if the underlying is above (or below) a specified level on a given date, usually the maturity date of the product. Definition sourced from the www.structuredretailproducts.com glossary.
} 
consultation also asked whether the binding regulation should concern other products that are not structured but are nonetheless complex and/or risky. The consultation period closed in October 2011 with a feedback statement on the consultation published in July 2012.

\section{A 'soft law' approach has been a way of driving a level playing field in an important} product market. A legislative basis for product intervention might pose issues under European law, with insurance products and deposits carved out. A 'soft law' approach also provides a way for regulators to respond in a significantly more timely way to market change and innovation than may be possible under 'hard law' regulation. A move to 'hard law' on the other hand, provides industry with certainty, reduces opportunities for inconsistent application and interpretation and allows for other regulatory approaches (including rules about product governance) to be applied.

\section{Whether a hard or soft law approach is taken the regulatory regime will need to} consider and address a number of issues:

- The scope of the regime. Consideration should be given to extending the regime to cover other products posing similar misselling and information asymmetry risks to investors. The FSMA is considering work, for instance, in relation to Constant Proportion Portfolio Insurance (CPPI) products which, though complex, pose risks to investors similar to those posed by complex products caught by the Moratorium;

- Carve out threshold for complex products. Consideration should be given either to lowering the thresh hold (currently $€ 500,000$ ) or applying it to assets under management through all distributors. This would address some concerns that product choice for the more sophisticated investors has been needlessly reduced by the Moratorium; and

- Cross-border issues. Belgian issuers argue they are at a disadvantage when issuing products into European markets because they are required to impose a warning on product documentation that the product is a 'complex product' under Belgian law (even though it is not sold directly into Belgium). This was an issue raised in discussions with industry with the current Moratorium. This raises the more general issue of whether Belgium should work to develop a co-ordinated European response to these issues.

\section{SYSTEMIC RISK AND REVIEWING THE REGULATORY} PERIMETER

\section{IOSCO has introduced new principles dealing with supervision and regulation in} response to the crisis. In June 2010, IOSCO approved a revised set of Objectives and Principles of Securities Regulation which included a number of new Principles, including the following: 
- Principle 6: The Regulator should have or contribute to a process to monitor, mitigate and manage systemic risk, appropriate to its mandate; and

- Principle 7: The Regulator should have or contribute to a process to review the perimeter of regulation regularly.

The accompanying IOSCO Methodology sets out key features and definitions which provide for some flexibility in implementing the Principles.

57. The open nature of the Belgian financial system, the regulatory architecture, and the relatively small size of the FSMA influence what is appropriate for implementation of these Principles. The NBB has the primary role in relation to systemic risk. The FSMA is obliged to share information with the NBB on systemic risk issues but formal processes are missing. Within its more limited role, the FSMA is taking steps to address the objectives of the new IOSCO Principles. The Management Committee of the FSMA is required to take cognizance of developments and general questions including systemic and structural issues which influence areas within the FSMA's competence. ${ }^{26}$ A number of recent initiatives provide examples of monitoring and addressing systemic risks:

- The Moratorium, which is seen as reducing the risk of misselling and large scale loss by investors (similar to that experienced in the wake of the Crisis); and

- Construction of a profile of Belgian household assets. This provided the basis for identifying the most significant asset classes for Belgian households and the areas in which regulatory initiatives may need to be explored or taken. This contributed to a focus on reforms to regulated savings accounts which, as the largest single asset class for Belgian investors, are viewed as systemically important.

- Building systemic risk monitoring capacity in-house.

\section{Processes around systemic risk monitoring and management are ad hoc. The FSMA}

should develop more formal processes which allow it to consider and analyze the risks the activities for which it is responsible may pose and whether such risks contribute to or create broader systemic risks. A systematic approach will reduce the chances of systemic risks crystallizing before they have been fully identified and quantified. The FSMA needs to be able to point to comprehensive risk analyses and research to enable it to identify early sources of risk within its purview and rely less heavily on the experience of particular individual senior staff and management Committee members. Stand alone processes would also create a framework through which senior staff could stand back from day-to-day transactional activity to review the environment and the risks posed to the areas of FSMA responsibility.

${ }^{26}$ Article 49 (5) of the Law of 2002. 
59. A Standing Committee should be established to formalize monitoring and assessment of systemic and other emerging risks. The Committee should have responsibility for assessing emerging issues and risks (including systemic issues and risks). It should meet regularly to discuss reports and intelligence, information sourced from the NBB and analyses of complaints reported to Departments across the FSMA (supplemented by reporting received from Ombudsfin). The Committee should also discuss ways in which risks identified might be managed and mitigated. Outcomes of the deliberations of the Committee should be shared with the NBB.

\section{There is good evidence of the FSMA continuing to monitor and respond to market}

developments. The FSMA has a good awareness of the need to monitor and assess developments in and around its regulatory perimeter on an ongoing basis. Examples are its recent work on disclosure in relation to regulated savings accounts and upcoming legislation to empower the FSMA to undertake mystery shopping (as a means of monitoring and raising industry awareness of their compliance obligations). The Policy Department reviews regulatory policies on products, markets and market participants to assess if they are up to date and comply with developments in financial markets. ${ }^{27}$ The FSMA also draws the attention of financial consumers to the specific risks of such new products and services by publishing a warning on its website. Recent examples have included crowd funding (two initiatives, one addressed to promoters and one to consumers), financial planning offices (new legislation) and life settlement contracts (information to and warning of the public).

\section{Activity to date has reflected the strong commitment of the FSMA to ensuring the} regulatory perimeter remains under review and responsive to the developments seen in

Belgium and elsewhere. More formal and robust processes are needed to ensure that this commitment is a lasting part of the culture and systems of the FSMA. The creation of the Emerging Risk Committee recommended as a means of implementing Principle 6 would be an appropriate response.

\section{CONCLUSION}

\section{The focus on securities markets regulation has benefited from the restructuring of} regulation along function lines. The authorities should continue efforts to solidify the cooperation and integration of work between the NBB and FSMA, embed the process for monitoring systemic risk at the FSMA and press ahead with investor education work. The FSMA's initial work on structured products sold to retail consumers should be further solidified and expanded.

\footnotetext{
27 The FSMA also designs its supervision programs to take into account its observations about the risks posed by products, markets and market participants to investor protection, efficient and transparent markets and to the reduction of systemic risk. The action plan is based on a preliminary analysis of the economic situation and of the possible emergence of risks posed by products, markets and market participants to investor protection, to efficient and transparent markets and to the reduction of systemic risk. The preliminary analysis is made up of risk-based analysis within the ESMA and IOSCO colleges, and on the conclusions of the ongoing dialogue with professional organizations.
} 


\section{Appendix I. Financial Services Institutions in Belgium Subject to FSMA Regulation ${ }^{1}$}

1. Credit Institutions. This segment comprises 48 banks governed by Belgian law (of which 21 are domestic and 27 foreign) and 59 branches of institutions governed by the laws of other countries. The six largest banks account for over 70 percent of the market (measured by asset value). The total number of banks authorized to do business in Belgium has fallen slightly since 2006 with an increase in the number of institutions operating through branches.

2. Insurance Firms. This segment includes 94 insurance firms with the six largest accounting for 60 percent of the market (measured by asset value). There has been a 10 percent drop in the number of insurance firms operating in Belgium since 2006.

3. Investment Firms. This segment includes 22 stock broking firms (five fewer than in 2006) and 20 investment advice and portfolio management companies (two fewer than in 2006 with the five largest accounting for over 70 percent of the market measured by asset value). Stock broking firms hold client assets. Other investment firms do not. Investment Advice and Portfolio Management Services act as brokers providing specific advice about securities and structuring portfolios.

4. UCITS Management Companies. This segment includes 64 companies managing 1,936 UCITS. Of these companies, seven are governed by Belgian law with the remainder governed by the laws of other European Economic Area (EEA) jurisdictions. The seven Belgian companies are all members of financial services conglomerates, with the four largest subsidiaries of one, or other, of the four main banks.

5. Intermediaries. This segment comprises over 3,900 banking and financial services intermediaries, 13 banking and financial services brokers, over 9,000 insurance intermediaries and just over 8,000 insurance brokers. Banking intermediaries receive funds from clients, provide investment services and supply investment products and must be tied to a particular credit institution or firm which is responsible for supervising its activities. Banking brokers are not able to receive client funds. There has been a significant decline in the number of intermediaries since 2006, with a drop of 25 percent in the number of insurance intermediaries and 10 percent in the number of banking intermediaries.

\footnotetext{
${ }^{1}$ Source: FSMA, FSMA Annual Report, http://www.fsma.be/en/Doormat/Publications/Annual\%20reports.aspx
} 
6. Mortgage Companies. This segment comprises 117 firms which finance real estate purchases by households and commercial enterprises. Mortgage companies do not take deposits from the general public and are financed in wholesale markets. Again, there has been a marginal decline in the number of these companies active in Belgium since 2006.

7. Pension Funds. This segment comprises 245 funds, 25 percent fewer than in 2006. Funds range in size from the very large corporate pension funds to small funds with five or six beneficiaries.

8. Exchanges. The single largest stock market in Belgium is operated by NYSE-Euronext, formed through the 2007 merger of the NYSE and Euronext. The Belgium market operates alongside other European members of the Euronext Group in Amsterdam, London (Euronext Liffe), Lisbon and Paris. The NYSE-Euronext in Belgium lists 148 companies of which 118 are domestic (with market capitalization of $€ 219$ billion) and 30 foreign (with market capitalization of $€ 177$ billion). The exchange is the 8th largest in Europe measured by market capitalization. Other trading venues now active in Belgium include Chi-X, Turquoise, BATS, Equiduct and TOM (together with a market share in October 2012 of 34 percent).

9. Others. This segment comprises 13 bureaux de change and eight portfolio management companies operating through branches of companies from other EEA countries. 


\section{Appendix II. Addressing Recommendations of the 2006 FSAP}

\section{'Like-product' regulation}

1. The 2006 FSAP recommended that a review of 'like product' regulation should be conducted with a view to leveling, where possible in the context of European law, the playing field for UCITS. The recommendation is based on a requirement in the Methodology supporting assessment of Principle 1 of IOSCO's Objectives and Principles of Securities Regulation that the same types of conduct and products are generally subject to the consistent regulatory requirements. This requirement was retained in the 2011 revisions to the Methodology. The 2006 FSAP expressed some concern that while CIS were subject to considerable regulation in Belgium, there were products developed by insurance companies (similar to investment products) that were not subject to equivalent regulation.

\section{Progress has been made in addressing these recommendations, generally reflecting}

legislative initiatives under European law. Where action has not been taken, European law is cited as a constraint (particularly in relation to the insurance sector). The FSMA's approach indicates a good understanding of the impact of arbitrage risks created by differences in regulation on investors.

\section{The FSMA's approach has involved both legislative and soft law responses. UCITS and} notes are now subject to the same conduct, disclosure and advertising requirements. These requirements do not apply in the same way to products sold through an insurance wrapper due to European law requirements. For instance, restrictions remain on the ability of Member States to require preapproval of investment policy or fee disclosure documents for 'CIS equivalent' insurance products. ${ }^{1}$ The FSMA has pursued 'soft law' methods of achieving the level playing field. It is, for instance, working with industry to develop guidance on disclosure consistent with requirements in other sectors. The Moratorium has given the FSMA the opportunity to apply a consistent approach across all product classes including insurance products (which now account for the lion's share of products in this market).

\section{These initiatives have been underscored by combining operational responsibility in the} FSMA for all products into one department. Processes within this department have been developed to ensure consistent application of the Moratorium across product classes. Decisions are reviewed at a single point, with input from teams with expertise in each product class.

\footnotetext{
${ }^{1}$ Directive 2002/83/EC of the European Parliament and of the Council of 5 November 2002 concerning life assurance.
} 


\section{Investor education}

5. The 2006 FSAP recommended the CBFA develop investor education programs. At the time of the 2006 FSAP, there were no programs in place.

\section{The FSAP has developed a strategy to address this recommendation which reflects} international best practice. The establishment of the FSMA, with a legislative mandate to contribute to the better education of financial consumers, provided an opportunity for the FSMA to address these recommendations. The FSMA created an investor and consumer relations department and hired experts with a communications and marketing background. Experts with this background are better positioned to understand consumer behavior (including how decisions are made and how information is processed) than those from traditional securities regulatory backgrounds. The new team developed a strategy to guide the FSMA's thinking. The strategy reflects international best practice and is long term in focus.

\section{The core of the strategy is to become a trusted partner focused on empowering} investors by building their skills on money matters and providing well targeted information at key life moments. The strategy focuses on education to raise awareness of financial issues rather than teaching investors how to make decisions. The early strategy is to focus on young people - both at school and at an early stage of life. An important focus is on education in schools and positioning the FSMA as a trusted source of information. Key initiatives include the following (which are to be progressively rolled out through 2013 and beyond):

- Developing a single trusted portal which provides access to financial information tailored to different life stages. This will be launched in early 2013 (as wikifin.be) and supported by a simulator which investors can use to compare savings products;

- Supporting the integration of financial education into Belgian schools through providing exchange platforms and developing materials to support teacher training; and

- Developing as a meeting place for stakeholders. Conferences are proposed and have been held to bring together Belgian stakeholders on financial education issues.

\section{Transparency of enforcement programs}

\section{The 2006 FSAP recommended that steps be taken to increase the transparency of} enforcement processes. The FSAP noted that the CBFA had all the necessary powers to carry out inspections and investigations, a wide range of sanctioning powers and thorough and well planned inspection programs, it needed to ensure these processes were visible to the public. The FSAP also 
recommended that application of administrative sanctions should be published as a matter of course (subject to exemptions where the public interest may be damaged). Transparency in these areas is key to ensuring a regulator is seen to deliver effective enforcement programs. Transparency provides credibility to a regulator's aspirations to be an effective 'cop on the beat'.

\section{The CBFA and the FSMA have progressed this recommendation in the context of new} investigation and enforcement procedures and new procedures for imposing administrative sanctions. Procedures were introduced in July 2011 supported by the establishment of the Enforcement Service responsible for supporting investigation activity. The reforms are intended to improve the efficiency of the investigation and enforcement process and bring a greater degree of independence into the decision making process (with a Sanctions Committee appointed comprising a mix of experts, judicial officers and government appointees). The new procedures contemplate a range of outcomes of an investigation including agreeing settlements and launching administrative sanctions proceedings. It is too early to test or assess the impact of these changes. Of the 19 cases referred to the Management Committee for action since the changes came into force, 12 have been referred to the Sanctions Committee. The Sanctions Committee has yet to finalize decisions in these matters.

\section{These changes provided an opportunity to change the public profile given to the}

FSMA's enforcement activity. All decisions in relation to administrative sanctions are now required to be published on the FSMA's website with the names of parties mentioned. There is scope for deleting names where publication seriously risks disrupting the financial markets or might cause disproportionate damage to the parties in question. Other decisions of the Management Committee (including decisions to close the case and informing the Public Prosecutor's office where criminal offences may be involved) may also be made public with the names of parties published. A decision to refer a matter to the Sanctions Committee for assessment is generally not publicized. Sanctions Committee decisions to impose administrative penalties may also be published, but only after the period for appealing the decision to the Brussels Court of Appeal has expired. Names are also not published where an appeal is lodged. In the 18 months since changes to the enforcement processes four announcements have been made. Agreed settlements and decisions of the Sanctions Committee are also published in the FSMA's Annual Report, although parties' names are not mentioned.

\section{Unlisted issuers}

11. The 2006 FSAP noted that the CBFA did not have sufficiently broad powers in relation to unlisted issuers (which the 2006 FSAP noted were a 'tiny' group in the Belgian market). The 2006 
FSAP recommended that the CBFA be granted direct authority and undertake ongoing supervision of unlisted issuers. It also recommended that unlisted issuers be subject to the material event disclosure requirements applied to other issuers.

\section{There has been no direct response to these recommendations with the FSMA}

continuing to focus on listed companies. The FSMA's response appears to reflect the limited number of unlisted issuers and restrictions under European law. The FSMA estimates that in the year to end December 2012, 7 unlisted issuers issued a total of 170,000 stock to Belgian investors. While neither European nor Belgian law impose material event disclosure requirements on unlisted companies, these companies continue to be subject to the Belgian common law and must respect the rules regarding the fair treatment of their investors and consumers. The FSMA notes that it supervises unlisted companies once they undertake a public offering using a prospectus and has authority and has taken action in relation to public offerings made without a prospectus approved by the FSMA. Despite this, investors in unlisted issuers do not benefit from the disclosure obligations applied to listed issuers.

\section{Insider transactions}

13. The 2006 FSAP recommended that the concept of 'insider' be introduced into these requirements with a reporting system developed and reports made public. The 2006 FSAP noted that transaction reporting requirements are in place for large shareholders (as required by relevant IOSCO Principles) but not in relation to officers, directors and related parties. It also proposed that the five percent threshold on reporting be removed.

\section{These recommendations have been addressed through transposing European law into}

Belgian Law. Insider transaction reporting was introduced in implementing the EU Market Abuse Directive (MAD). The Belgian system has been operational since May 2006. ${ }^{2}$ Reporting obligations now apply not only to members of corporate governing bodies, but also to senior management discharging managerial responsibilities, and to natural or legal persons closely related to those board members and senior managers (e.g. spouses/husbands, children and patrimonial companies owned by insiders).

\section{Transactions are also reported to the FSMA and published on its website. Since} introduction of the requirement, over 6,500 transactions with a total value of over $€ 11$ million have been reported The FSMA highlights the popularity of this information with the general public. On

\footnotetext{
${ }^{2}$ Article $2,22^{\circ}$ and $23^{\circ}$ of the Law of 2 August 2002.
} 
average 3,000 hits are made per month on the relevant page indicating a high level of public interest.

\section{Removing above-market price requirements from takeover bid rules}

16. The 2006 FSAP recommended that change of control requirements be strengthened. It was suggested that the introduction of a thresh hold may provide greater guidance to the market and provide investors additional protection. It was also recommended that the requirement that an investor acquiring control do so through an above-market price be removed from Belgian law.

\section{This recommendation has also been addressed through changes in European law} transposed into Belgian Law. In 2007, through the Law of April 1, 2007, the FSMA transposed the European Directive (2004/25/CE) relating to Takeover Bids into Belgium. The Law removed the requirements from takeover bid rules, subject to a condition that any person holding more than 30 percent of voting securities must launch a full takeover bid for all voting securities in the company. ${ }^{3}$

\section{Bearer shares}

\section{The 2006 FSAP noted a number of issues relating to the use of bearer shares in}

Belgium. These are shares which are not registered on the registry of a company but are fully transferrable without the need to record the transfer. The 2006 FSAP recommended that the use of these shares be eliminated because of the opacity risks they pose.

\section{Legislation in late $\mathbf{2 0 0 5}$ laid out a road map for the gradual abolition of bearer shares.}

The milestones for this road map—although somewhat distant—give issuers and shareholders the opportunity to arrange their affairs accordingly. The FSMA is monitoring progress informally through discussions with EuroNext. The following steps have been taken (or are contemplated) in what is described as a dematerialisation process:

- From January 1, 2008, Belgian companies were no longer able to issue bearer securities. From that date, existing bearer securities held in securities accounts could also no longer be physically delivered as bearer securities. The FSMA estimates that bearer shares issued by listed issuers currently in circulation are valued at $€ 42$ million, a not insignificant amount;

- From January 1, 2014, all bearer securities will be converted to 'dematerialised or nominative securities' and registered on the account of the issuer, until the owner of the original bearer

\footnotetext{
${ }^{3}$ Article 5 of the Law of April 1, 2007.
} 
securities requests registration in its name. Requests to do so must be made by the end of 2014; and

- Converted securities that have not been claimed by the owners by January 1, 2015 must then be sold by the issuer. The proceeds of these sales will be paid into the public Deposits and Consignments Fund, from which owners of the original bearer securities may claim their part of the proceeds, after deduction of transactions costs, and, from January 1, 2016, a further 10 percent deduction.

The financial sector has set up a website dedicated to the entire process of dematerialisation. Arrangements are in place to give effect to the 2014 deadline. ${ }^{4}$

\section{Written agreements for customers of market intermediaries}

\section{The 2006 FSAP required intermediaries to have written agreements for customers.}

Under Article 27, $\$ 7$ of the Law of 2002, intermediaries are now required to have a separate client file containing the documents describing the rights and obligations of both parties and the terms and conditions of the provision of services to the client. For retail clients, a written basic agreement laying out the main rights and obligations of the parties is mandatory. These requirements took effect in November 2007 when MiFID requirements were transposed into Belgian law.

\section{Complaints registers}

\section{The 2006 FSAP recommended that market intermediaries keep a register of client} complaints. This has been addressed by recent European initiatives translated into Belgian law (Article 16 of the MiFID Regulation of the CBFA of June 5, 2007 approved by Royal Decree of June 19, 2007). These requirements will also be the subject of MiFID conduct reviews.

\section{Coordination of Euro-next oversight}

22. The 2006 FSAP noted good progress in co-ordinating oversight of the only regulated stock exchange in Belgium and recommended this progress be continued. Cooperation initiatives reflect changes arising from the merger of NYSE and Euronext:

- In 2007, the College of Euronext Regulators (AFM (Netherlands), AMF (France), FSMA, CMVM (Portugal) and FSA (U.K.)) signed an MOU with the U.S. Securities and Exchange Commission

\footnotetext{
${ }^{4}$ http://www.dmat.be/index.html?page $=0$
} 
(SEC) concerning consultation, cooperation and the exchange of information related to market oversight. The MOU expressed the willingness of the SEC and the College of Euronext Regulators to cooperate with each other in the interest of fulfilling their respective regulatory mandates, particularly in the areas of investor protection, fostering market integrity, and maintaining investor confidence and systemic stability; and

- In July 2010, the FSMA signed an updated MOU with the AFM, AMF, CMVM and FSA about the coordinated regulation and supervision of the European regulated markets operated by the Euronext Group and of Euronext NV). This MOU was set up to better reflect the changes within the Euronext group and the evolution of financial supervision. 